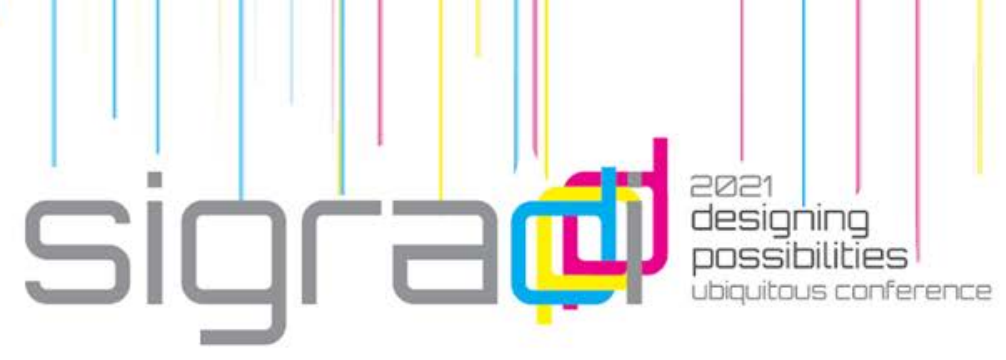

\title{
Smart cities, smart housing, smart habitat: are we there yet?
}

\author{
Pedro Soza Ruiz ${ }^{1}$, Bruno Perelli Soto ${ }^{1}$, Ricardo Tapia Zarricueta ${ }^{1}$ \\ ${ }^{1}$ Universidad de Chile, Chile \\ psoza@uchile.cl \\ bperelli@uchile.cl \\ rictapia@uchilefau.cl
}

\begin{abstract}
This paper presents the results of a study seeking to understand users' attitudes regarding their consumption and use of the Internet, IOT devices, and related technologies. The framework of the study reviews the concept of Smart City, presents the position of Santiago (capital of Chile) within a world index of Smart Cities, and draft the status of three housing complexes located in highly vulnerable areas in Santiago in light of such an index. Further, we discuss what is missing to solve the gap between current trends and the image of Santiago as a real Smart City in Latin America.
\end{abstract}

Keywords: Smart Cities, Internet of Things (IoT), Santiago de Chile, Survey.

\section{Introduction}

Like the concept of the Internet of Things (IOT), the notion of Smart City is still elusive. During the last ten years, scholars have dedicated themselves to defining what Smart Cities are. For example, Gonzales and Rossi (2011) referred to the concept from the European Platform for Intelligent Cities (EPIC) analysis. They pointed out that smart cities are based on information and communication technologies at a conceptual level and have all the characteristics associated with organizational, technological, economic, and social development change in a modern city. Neirotti et al. (2014) also focused on providing a comprehensive understanding of the notion of Smart City. Their work proposed a taxonomy of application domains that articulates the interaction of natural resources and energy, transport and mobility, buildings, government, economy, and people. It revealed that the evolution patterns of a Smart City depend significantly on the factors of the local context. However, the 
authors say, we do not yet have a shared definition of Smart City and that it is difficult to identify common global trends. Ojo et al. (2016) mapped several academic publications focused on the Smart Cities domain. Its objective was to synthesize an emerging understanding of the smart city concept and determine the main research themes, types, and gaps in the current research landscape. They concluded that Smart Cities as urban innovation and transformation initiatives aim to take advantage of physical infrastructures, information, communication technologies (ICT), knowledge resources, social infrastructure for economic regeneration, social cohesion, better administration of the city, and infrastructure. Silva et al. (2018) are also among those who claim that the concept of Smart City is still evolving and has not become widespread around the world due to technological, economic, and government barriers. Likewise, Pal et al.(2018), whose research focuses on the cutting-edge efforts directed towards analyzing big data in the context of smart cities, also claim that the concept of Smart City is a paradigm even in evolution.

On the other hand, Kirimtat et al. (2020) point out that Smart Cities have emerged because of highly innovative ICT industries and markets. In addition, they use novel solutions taking advantage of the Internet of Things (IOT) technologies, big data, and cloud computing to establish a deep connection between each component and layer of a city. Among all these efforts, there are two that have especially caught our attention. First, Albino et al. (2015) stated that Smart Cities are multi-faceted, a concept by which they expanded the notion to include the qualities of people and communities. However, a universal concept, these authors indicate, can be difficult to define given the variety of characteristics of cities worldwide. In this regard, they present an account for approximately 143 self-designated Smart City projects in progress or completed. Among these initiatives, North America had 35 projects; Europe, 47; Asia, 50; South America, 10; and the Middle East and Africa, 10 (Lee et al., 2014).

Along the same line, Berrone and Ricart (2020) proposed the cities in motion index (CIM), which was introduced to analyze 77 city indicators that cover ten dominant categories in urban life, that is, economy, technology, human capital, cohesion. social, international reach, environment, mobility and transport, urban planning, public management, and governance. Berrone and Ricart evaluated 181 cities in more than 80 countries to determine which were the smartest cities in the world. Based on their index results, the cities of New York (US), London (UK) and Paris (France) topped the list respectively, while San Francisco (US), Boston (US), Amsterdam (Netherlands), Chicago (USA), Seoul (South Korea), Geneva (Switzerland) and Sydney (Australia) complete the top 10. These researchers indicate that this type of ranking is relevant because it makes it possible to improve cities' competitiveness and improve the 


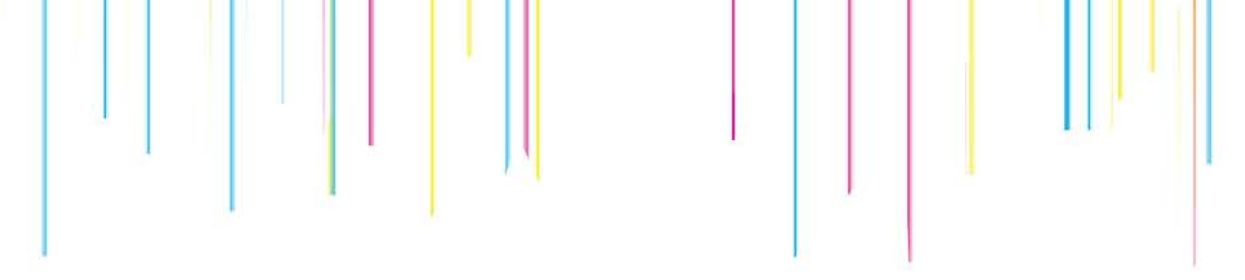

sustainability and habitability of Smart Cities in the real world. Santiago de Chile, in our case, is ranked 68 in the 2020 index.

\begin{tabular}{|c|c|}
\hline Category & Ranking \\
\hline Governance & 94 \\
\hline Urban planning & 40 \\
\hline Technology & 94 \\
\hline Environment & 29 \\
\hline International outreach & 62 \\
\hline Social cohesion & 80 \\
\hline Mobility and Transportation & 42 \\
\hline Human capital & 97 \\
\hline Economy & 103 \\
\hline Santiago (Chile) & 68 \\
\hline
\end{tabular}

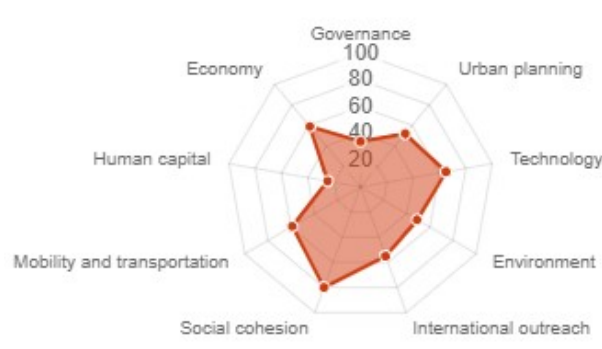

Figure 1: Dimensions for Santiago de Chile. Smart cities index. Image by: Soza, Perelli, Tapia, 2021.

As can be seen, while the term "Smart City" continues to gain more and more popularity, there is still confusion about what a smart city is, mainly because various dimensions of analysis that make up the concept are often used interchangeably.

In our case, with a slightly different approach in our previous work, we began to develop a taxonomy centered on people, to understand the use of IoT technologies in the context of Latin American cities that aspire to become Smart Cities. However, we shifted the focus of our previous study to understanding the use of IoT in the context of the pandemic (Perelli, 2020). We based our incipient taxonomy on the adoption of the superposition of the three leading technologies that define Smart Cities: IoT; Al, and Big Data (Javaid, 2020; Perelli, 2020), with the role of the contexts in the places where these three technologies are implemented (Kummitha, 2017, 2020; Perelli, 2020).

Thus, in this paper, we analyze whether the use of loT in pandemic contexts is transferable to developing vulnerable urban contexts that aspire to become Smart Urban Contexts. Our analysis, centered on people, focused on the adoption of 4 dimensions commonly found in the reviewed literature: connection and accessibility to the Internet, use of the Internet and its technologies and devices, for what they use the Internet and its technologies and devices, and which it is their attitude and perception towards the Internet and its associated technologies.

In this article, we present the results that emerged from evaluating the reality of 3 different housing complexes in vulnerable urban contexts of Santiago de Chile, which occupies position 68 of the CIM index (Fig. 1). 


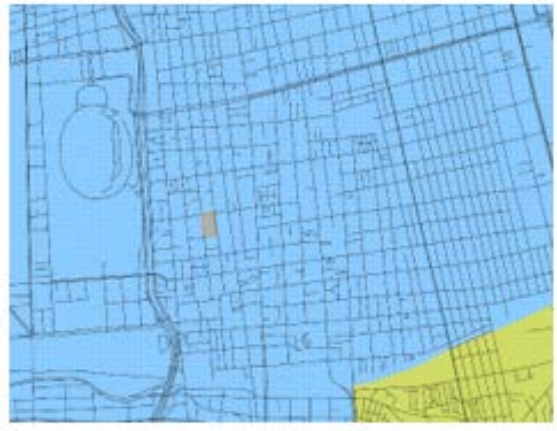

Figure 3: Conjunto Andalucía in Santiago's most connected zone (in blue). Source: Soza, Perelli, Tapia, 2021.

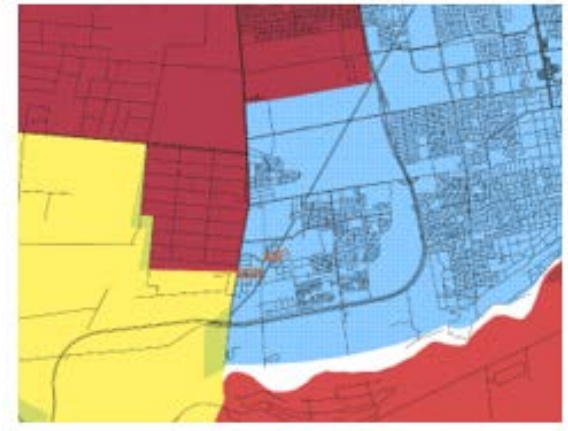

Figure 4: San Miguel 2 \& 4 within Santiago's most connected zone (in blue). Source: Soza, Perelli, Tapia, 2021

\section{Results}

Ninety people, residents of the three housing complexes, answered the survey. Below, we present these results grouped in four sections.

\subsection{Internet connectivity}

93.2\% (82 responses) of the participants indicated having access to the Internet in their place of residence (Fig. 5). However, the results also revealed that $67.4 \%$ of said connectivity occurs through smartphones (smartphones), so we believe that at least $2 / 3$ of such connectivity is ubiquitous. Indeed, $67 \%$ of those who responded indicated that they did so by sharing or using a cell phone data plan, versus $36 \%$ who indicated that they connected using optical fiber or $31.8 \%$ who indicated do it through an ADSL (broadband) connection (Fig. 6).

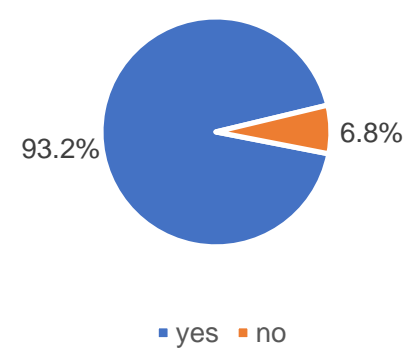

Figure 5: Do you have Internet in the place where you currently live? Source: Soza, Perelli, Tapia, 2021. 


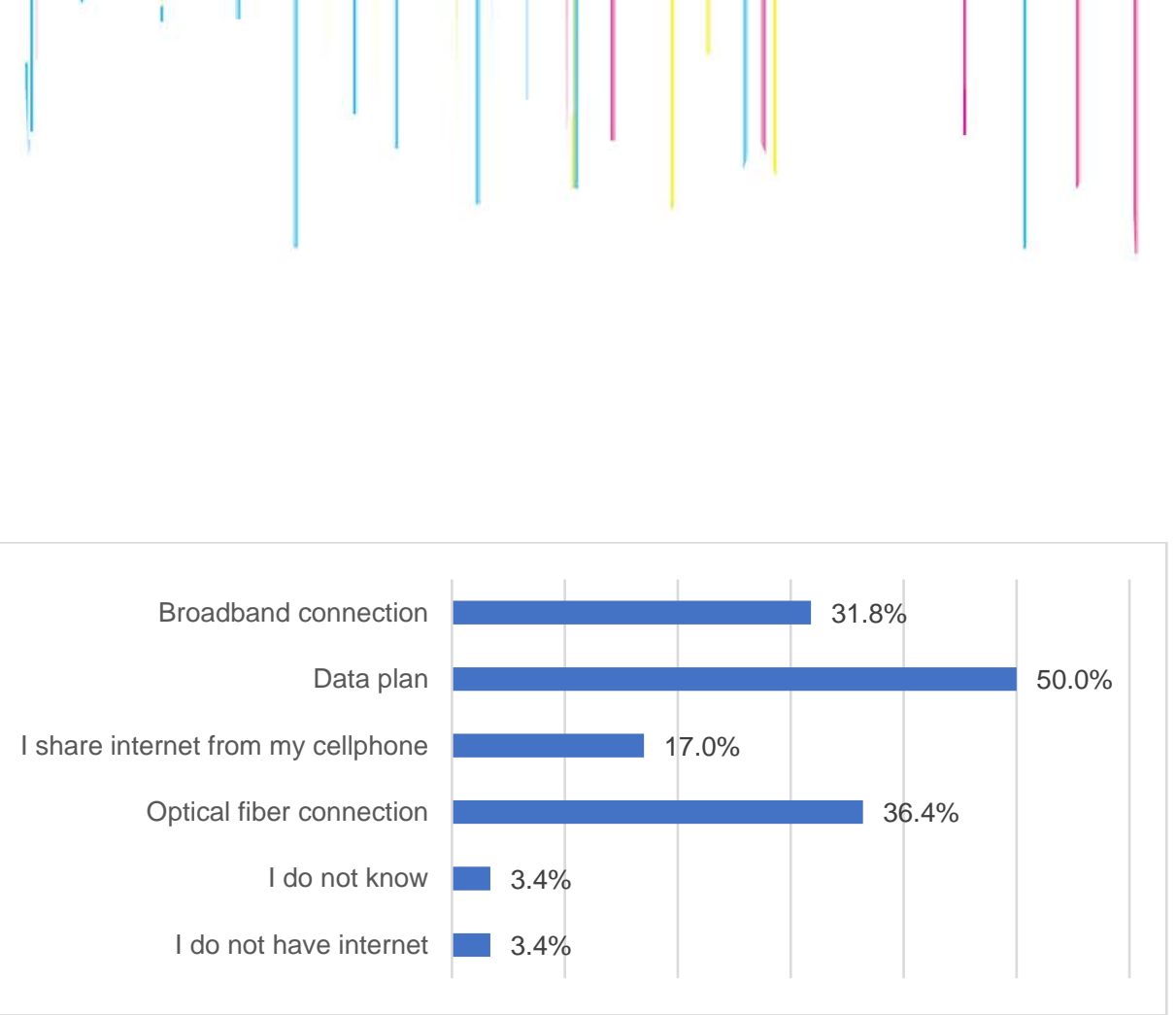

Figure 6: Tell us all the ways you use to connect to the Internet in the place where you currently live. Source: Soza, Perelli, Tapia, 2021.

Regarding the devices used to connect to the Internet, the results show that, although we are still in an initial stage of adoption, the use of IoT devices is increasing. For example, regardless of connecting via smartphone or computer, 19 persons indicated connecting to the Internet through video game consoles, 49 using a Smart TV, and 35 using Wi-Fi audio systems. Seven reported using Wi-Fi video cameras, 11 users reported using smart lighting, and two indicated using internet-connected cleaning robots (Fig. 7).

Regarding the connection, $39.1 \%$ of those who responded indicated doing so through an unlimited data plan, 35\% a limited data plan, and $24 \%$ use prepaid plans, which shows how permanent connectivity has been gaining terrain and is seen by users as an urgent need.

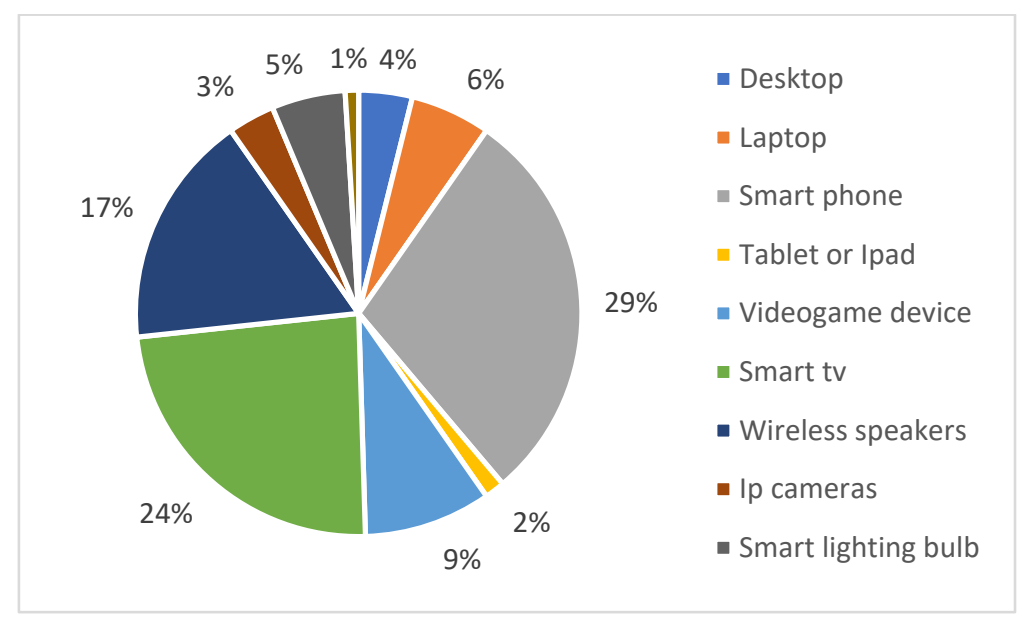

Figure 7: Of all the devices you use to connect to the Internet, which one do you use the most? Source: Soza, Perelli, Tapia, 2021. 


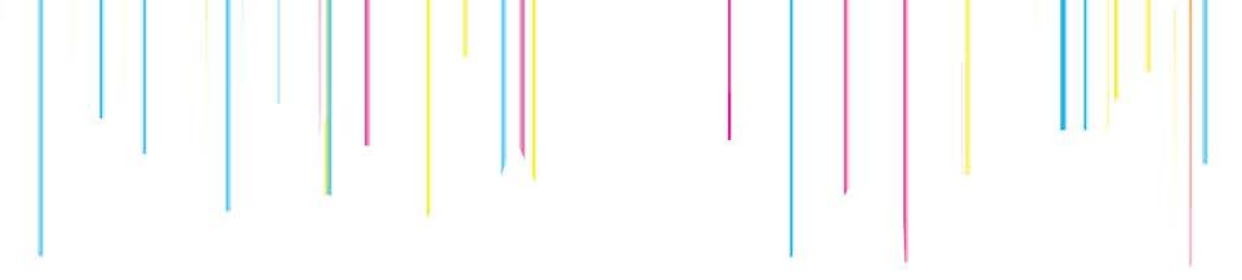

$13.3 \%$ from squares or public spaces, and $8.9 \%$ from schools. Only $5.6 \%$ of those who responded indicated connecting from the common spaces of their residential complexes (Fig. 9). We interpret this as a tremendous growth opportunity.

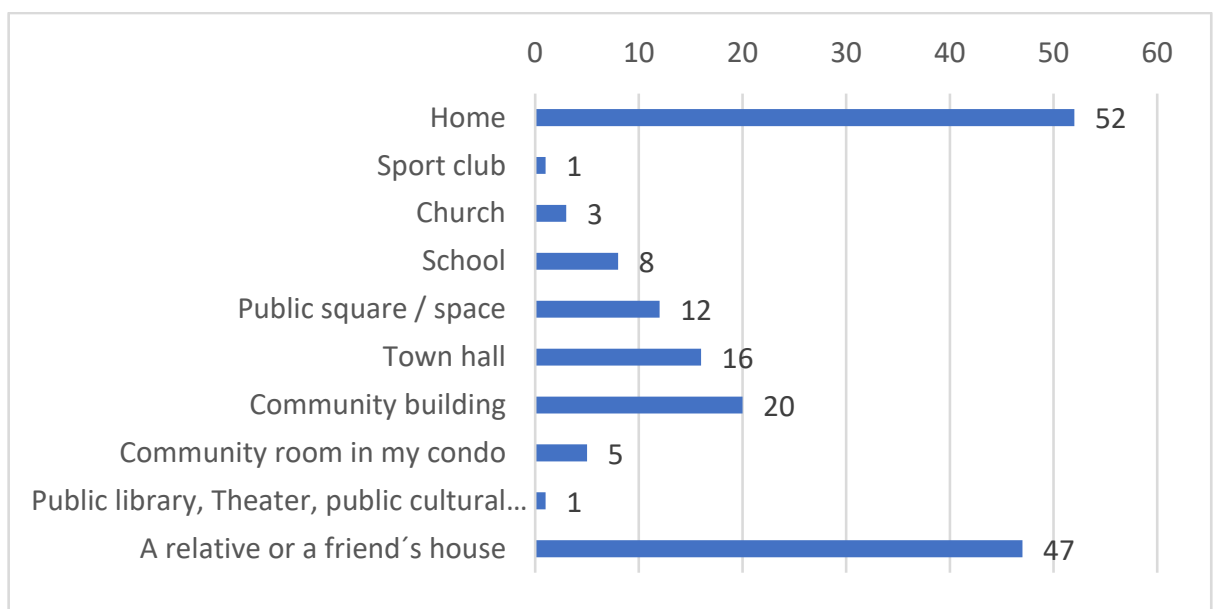

Figure 9: From where you and other members of your home have accessed the Internet in the last month. Source: Soza, Perelli, Tapia, 2021.

Regarding the concerns that respondents reported suffering when connecting online, $69 \%$ indicated that the most relevant thing was the security of their data, specifically concerned about how said information could be used (62.1\% of respondents). Protecting themselves from viruses and malware and protecting people in the family group - older adults or children - also captured a high response rate, with $59.8 \%$ and $58.6 \%$ of preferences, respectively.

\subsection{What do people do with the Internet, its technology, and devices}

This set of questions aimed to inquire why the participants use the Internet and its devices and technologies. We observe that all the alternatives given to the participants were selected to a greater or lesser extent. Table 1 shows the number of responses captured according to activities and time-frequency.

The first thing that stands out is that many responses are concentrated between the options daily use and never. Strikingly, teleworking reached only 27 responses versus 62 people who indicated they did not work remotely. The connectivity classes and meetings also appear discreetly on $50 \%$ of the responses, with 54 responses, a figure that increases to 73 responses selected in the option to do homework or work for school, institute, or university. The number of responses attained by the alternatives; use of social networks, contact with family and friends, and use of entertainment services also called our attention. 
Table 1. Frequency and activities

\begin{tabular}{lc|c|c|c|c}
\hline & Daily & Weekly & Monthly & Yearly & Never \\
\hline Check and send emails & 57 & 14 & 8 & 1 & 20 \\
\hline Buy online & 17 & 8 & 29 & 14 & 31 \\
\hline Pay bills and bank services & 16 & 6 & 41 & 3 & 32 \\
\hline Online Work & 27 & 3 & 2 & 6 & 62 \\
\hline Run own business & 14 & 7 & 6 & 4 & 68 \\
\hline Attend classes, meetings, or webinars & 54 & 13 & 6 & - & 26 \\
\hline Doing homework & 73 & 7 & 1 & - & 19 \\
\hline Take online classes & 13 & 9 & 9 & 9 & 60 \\
\hline Study another language & 19 & 7 & 9 & 6 & 60 \\
\hline Keep in touch with family and friends & 72 & 7 & 2 & 1 & 16 \\
\hline Using social networks & 83 & 3 & 1 & - & 11 \\
\hline Streaming services & 61 & 6 & 3 & 2 & 28 \\
\hline Listen to radio/music online & 64 & 9 & 6 & 3 & 18 \\
\hline Create and publish digital content & 16 & 14 & 6 & 10 & 54 \\
\hline Check government information & 23 & 7 & 20 & 12 & 38 \\
\hline Apply to social benefits & 19 & 16 & 31 & 14 & 20 \\
\hline Look for job & 24 & 9 & 8 & 12 & 47 \\
\hline Seek legal advice online & 18 & 8 & 11 & 19 & 44 \\
\hline Seek medical information online & 29 & 14 & 19 & 10 & 27 \\
\hline Seek properties online & 8 & 6 & 7 & 16 & 64 \\
\hline Look for solutions to any problem & 37 & 18 & 9 & 11 & 26 \\
\hline Call mobility services (Uber, Lift, Others) & 30 & 26 & 13 & 6 & 26 \\
\hline
\end{tabular}

Source: Soza, Perelli, Tapia, 2021.

We speculate that connectivity problems are not the cause of poor use of the Internet to search information or work, but rather we think that there are practical and even cultural reasons that might explain these results.

\subsection{Perception and attitudes towards Internet and technology}

When asked how important the Internet and its associated technologies are in their daily lives, approximately $88 \%$ of the respondents indicated that the Internet and its associated technologies are essential in their daily lives, ranging from extremely important, very important, and essential (Fig. 10). In contrast, $12 \%$ of the respondents indicated that the Internet and its technologies are not relevant to their daily life. 


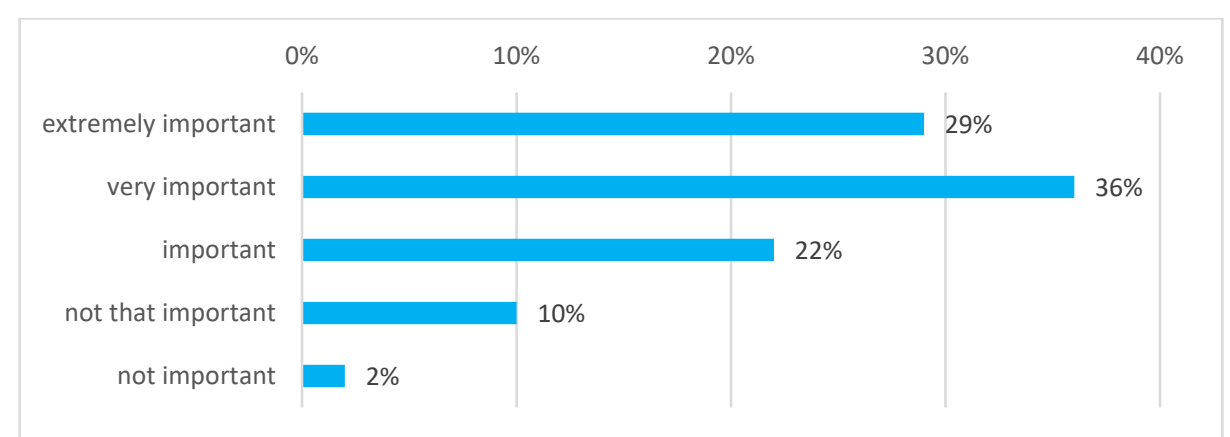

Figure 10: Importance for daily life. Source: Soza, Perelli, Tapia, 2021.

On the other hand, when consulting people about the level of benefits that the Internet and its technologies give to their life, family, and society, the vast majority of those consulted indicated that they saw positive effects, although also counterproductive (30\% family and $33 \%$ for society). Only between 6 and $5 \%$ of those consulted indicated that they saw adverse or harmful effects from using the Internet and its associated devices and technologies for both their family and society (Fig. 11).

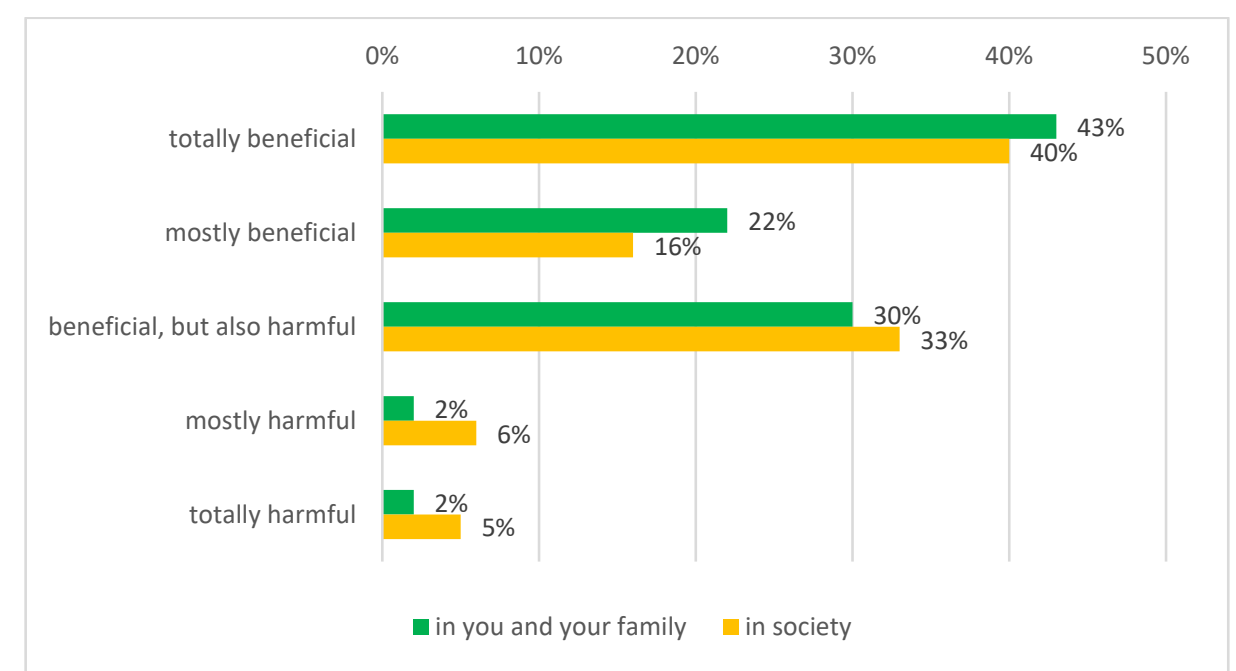

Figure 11: Effects on your family and society. Source: Soza, Perelli, Tapia, 2021.

Finally, when asked about what type of communication they preferred, the responses selected by those surveyed indicate a mixture of all the alternatives presented, with a great preponderance of social and communication networks, over virtual or even face-to-face meetings (Fig. 12). 


\section{References}

Albino, V., Berardi, U., \& Dangelico, R. M. (2015). Smart Cities: Definitions, Dimensions, Performance, and Initiatives. Journal of Urban Technology, 22(1), 3-21. https://doi.org/10.1080/10630732.2014.942092

Berrone, P., Ricart, J. E. (2020). IESE Cities in Motion Index 2020. IESE Business School University of Navarra.

González, J. A. A., Rossi, A. (2011). New trends for smart cities. Opencities, Manchester.

Javaid, M., Haleem, A., Vaishya, R., Bahl, S., Suman, R., \& Vaish, A. (2020). Industry 4.0 technologies and their applications in fighting COVID-19 pandemic. Diabetes \& Metabolic Syndrome: Clinical Research \& Reviews, 14(4), 419-422. https://doi.org/10.1016/j.dsx.2020.04.032

Kirimtat, A., Krejcar, O., Kertesz, A., \& Tasgetiren, M. F. (2020). Future Trends and Current State of Smart City Concepts: A Survey. IEEE Access, 8, 86448-86467. https://doi.org/10.1109/access.2020.2992441

Kummitha, R. K. R. (2020). Smart technologies for fighting pandemics: The techno - and human - driven approaches in controlling the virus transmission. Government Information Quarterly, 37(3), 101481. https://doi.org/10.1016/j.giq.2020.101481

Kummitha, R. K. R., \& Crutzen, N. (2017). How do we understand smart cities? An

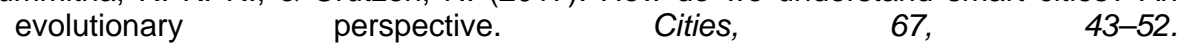
https://doi.org/10.1016/j.cities.2017.04.010

Lee, J. H., Hancock, M. G., \& Hu, M. C. (2014). Towards an effective framework for building smart cities: Lessons from Seoul and San Francisco. Technological $\begin{array}{llll}\text { Forecasting } \text { and } \quad \text { Social 80-99. } & \text { Change, }\end{array}$ https://doi.org/10.1016/j.techfore.2013.08.033

Neirotti, P., de Marco, A., Cagliano, A. C., Mangano, G., \& Scorrano, F. (2014). Current trends in Smart City initiatives: Some stylised facts. Cities, 38, 25-36. https://doi.org/10.1016/j.cities.2013.12.010

Ojo, A., Dzhusupova, Z., Curry, E. (2016). Exploring the nature of the smart cities research landscape. In Smarter as the new urban agenda (pp. 23-47). Springer.

Pal, D., Triyason, T., \& Padungweang, P. (2018). Big Data in Smart-Cities: Current Research and Challenges. Indonesian Journal of Electrical Engineering and Informatics (IJEEI), 6(4). https://doi.org/10.11591/ijeei.v6i4.543

Perelli, B., Soza, P., Tapia, R. (2020). Towards the development of Smart Buildings: A Lowcost IoT Healthcare Management Proposal in Times of a World Pandemic. Proceedings of the 24th Conference of the Iberoamerican Society of Digital Graphics, SIGraDi (pp. 586-593). Online Conference. http://papers.cumincad.org/cgibin/works/Show?sigradi2020_586

Silva, B. N., Khan, M., \& Han, K. (2018). Towards sustainable smart cities: A review of trends, architectures, components, and open challenges in smart cities. Sustainable Cities and Society, 38, 697-713. https://doi.org/10.1016/j.scs.2018.01.053 